\title{
Use of Transcranial Doppler in Intensive Care Unit
}

\author{
Sandor Viski ${ }^{1}$, Laszlo Olah ${ }^{*}$ \\ 1 Department of Family and Occupational Medicine, Faculty of Public Health, University of Debrecen, Debrecen, \\ Hungary \\ 2 Department of Neurology, University of Debrecen, Móricz Zs. krt. 22, H-4032 Debrecen, Hungary
}

\begin{abstract}
Use of transcranial Doppler has undergone much development since its introduction in 1982, making the technique suitable for general use in intensive care units. The main application in intensive care units is to assess intracranial pressure, confirm the lack of cerebral circulation in brain death, detect vasospasm in subarachnoid haemorrhage, and monitor the blood flow parameters during thrombolysis and carotid endarterectomy, as well as measuring stenosis of the main intracranial arteries in sickle cell disease in children.
\end{abstract}

This review summarises the use of transcranial Doppler in intensive care units.

Keywords: transcranial Doppler, intensive care unit, intracranial pressure, optic nerve sheath diameter, brain death, vasospasm, subarachnoid haemorrhage, thrombolysis, sickle cell disease, endarterectomy

Received: 13 July 2017 / Accepted: 21 July 2017

\section{INTRODUCTION}

Transcranial Doppler (TCD) was developed originally to detect vasospasm after subarachnoid haemorrhage [1]. However, since its launch in 1982, its use has widened to include diagnosis of stenosis or occlusion of the main intracranial arteries, measurement of cerebrovascular reserve capacity, examination of autoregulation and neurovascular coupling, microembolus detection and thus diagnosis of right-to-left shunt, ultrasound enhanced thrombolysis, assessment of increased intracranial pressure (ICP), detection of stop of brain circulation in brain death, and monitoring of cerebral circulation during carotid surgery or stenting, as well as during heart surgery. Moreover, development of transcranial colour-coded duplex (TCCD) examination allows the investigation of the cerebral parenchyma, the size of brain ventricles, and a more precise analysis of blood flow in the intracranial arteries. TCD is now extensively used in neurological disorders requiring intensive therapy.

The aim of this review is to summarise the potential applications of TCD and TCCD in intensive care units.

\section{THE BASICS OF TCD}

TCD uses relatively low frequency $(2.0-2.5 \mathrm{MHz}) \mathrm{ul}-$ trasound, as ultrasound at this frequency penetrates through the thinner parts of the skull, known as "bone windows". The ophthalmic artery and the carotid syphon can be viewed through the eye, the main intracranial arteries through the trans-temporal window, and the vertebral arteries and the basilar artery through the foramen magnum. The flow velocity in the extracranial part of the internal carotid artery used for calculation of the Lindegaard index in subarachnoid haemorrhage can be determined using a submandibular approach [2].

TCD examination allows the determination of flow velocity in the main vessels as well as the pulsatility index. It is important to emphasise that flow velocity in different individuals is not proportional to the blood flow, though flow velocity changes in one individual reflect the flow variations in the region of the insonated vessel $[3,4]$. The pulsatility index (PI) is calculated using the ratio of the difference of peak systolic (PSV) and end-diastolic flow velocity (EDV) and the mean flow velocity $(\mathrm{MV})$ i.e. $\mathrm{PI}=(\mathrm{PSV}-\mathrm{EDV}) / \mathrm{MV}$. [5] $\mathrm{PI}$ is 
a useful parameter for assessing the vascular resistance in the region of an insonated artery. With the use of head frames, TCD probes can be fixed to allow the continuous monitoring of flow parameters.

\section{InTRACRANIAL Pressure AND TCD}

Since the brain is enclosed in a rigid cavity, increase in the volume of any intracranial element leads to increased intracranial pressure. TCD is suitable for assessing intracranial pressure reducing the need for invasive measurement.

Increased intracranial pressure can be caused by cytotoxic or vasogenic oedema, tumors, hydrocephalus, and cerebral haemorrhage. An increase in intracranial pressure, more than the venous pressure, results in compression of veins and thus decreased venous outflow. Increase in ICP is accompanied by an increase in PI due to a decrease in diastolic and mean velocities [6].

PI larger than 1.26 was shown to be associated with an intracranial pressure more than $20 \mathrm{~cm} \mathrm{H}_{2} \mathrm{O}$ (sensitivity $81.1 \%$, specificity $96.3 \%$ [7]. Bouzat et al. (2011) showed that low end-diastolic flow velocity $(<25 \mathrm{~cm} / \mathrm{s}$; sensitivity $92 \%$, specificity $76 \%)$ and high PI (>1.25; sensitivity $90 \%$, specificity $91 \%$ ) indicated increased risk of secondary neurological deterioration in patients with mild to moderate traumatic brain injury with no severe brain lesions on CT [8]. Despite these data, pulsatility index alone does not seem to be a reliable predictor for intracranial pressure, but there is evidence that the autoregulatory index $(\mathrm{Mx})$ derived from blood flow velocity and arterial blood pressure measured non-invasively, is a useful parameter for assessing increased intracranial pressure in traumatic brain injury. Although more sophisticated analysis is necessary for assessment of dynamic cerebral autoregulation, poorer autoregulation was proven to be associated with poorer outcome and greater mortality in traumatic brain injury. Sorrentino et al. (2011) found that an autoregulation index $(\mathrm{Mx})$ of more than 0.3 clearly indicated disturbed autoregulation [9].

A significant correlation was shown between PI and ICP $(C C=0.938)$. Regression statistics revealed that the ICP value could be determined from the PI (ICP = $11.1 \mathrm{x}$ PI -1.43 ) with an error of $\pm 4.2 \mathrm{mmHg}$ compared to the actual ICP measured by an invasive method. ICP of more than $20 \mathrm{mmHg}$ was established with $89 \%$ sensitivity and $92 \%$ specificity [10].
In another study, a PI $\geq 1.56$ in patients with traumatic brain injury predicted a poor outcome at six months, while a PI $\leq 1$ identified patients with a favourable outcome [11].

At present, changes in pulsatility index values rather than absolute values can be used to assess an increase in ICP. Monitoring of flow parameters by TCD allows changes in PI to be monitored and a $1 \mathrm{mmHg}$ change in ICP was shown to equate to a PI change of $2.4 \%$ [12].

\section{OPTIC NERVE SHEATH DIAMETER AND INCREASED INTRACRANIAL PRESSURE}

In addition to flow parameters and auto-regulatory index, a more reliable indicator of increased intracranial pressure, namely the optic nerve sheath diameter (ONSD) has been widely used in the last decade. Although measurement of ONSD is based on B-mode ultrasound, and not on TCD, we consider it is important to describe this technique briefly.

The subarachnoid space surrounds the optic nerve and is bounded by the optic nerve sheath that is an anatomical extension of the dura mater. It is well known that an increase in the intracranial pressure results in swelling of the optic disc, i.e. papilla-oedema. However, development of papilla-oedema takes time, as is, therefore, a delayed indicator of increased intracranial pressure. Dilatation of the optic nerve sheath has been described as an early manifestation of a rise in intracranial pressure (Figure 1). [13, 14, 15] The optic nerve sheath can be examined by B-mode ultrasound with use of 7-11 MHz. ultrasound probe. The cut-off value for normal ONSD, measured at three $\mathrm{mm}$ posterior to the eye, ranges from 5.2 to $5.9 \mathrm{~mm}$ [15]. Although there is a relatively wide variation in the optimal cut-off values for normal ONSD [16,17], it seems to be a sensitive test for predicting elevated ICP. During the examination, the mechanical index has to decrease as little as possible, and the probe has to be placed lightly on the eyelids. The method cannot be used in patients with eye trauma or glaucoma [18]. Moreover, ONSD should not be considered in isolation, but must form part of a holistic approach towards the management of a patient with possible intracranial hypertension.

\section{口TCD IN BRAIN DEATH}

Brain death is defined as an irreversible cessation of brain stem functions that is associated with cerebral 
circulatory arrest caused by increased intracranial pressure. TCD is used as a confirmatory test to authenticate lack of cerebral blood flow.

With increasing ICP, TCD waveform shows highresistance profiles. At first, the diastolic flow velocity decreases then becomes zero, and if the intracranial pressure increases further, flow reversal occurs during diastole [19]. As cerebral perfusion pressure approaches zero, oscillating flow and small systolic spikes may appear (Figure 2), and finally no signal is detected $[19,20]$. Oscillating MCA flow pattern is characterised by equal systolic forward flow and diastolic reversed flow, i.e. net zero flow, indicating raised ICP and brain death. Systolic spikes of $<200 \mathrm{~ms}$ duration and $<50 \mathrm{~cm} / \mathrm{s}$

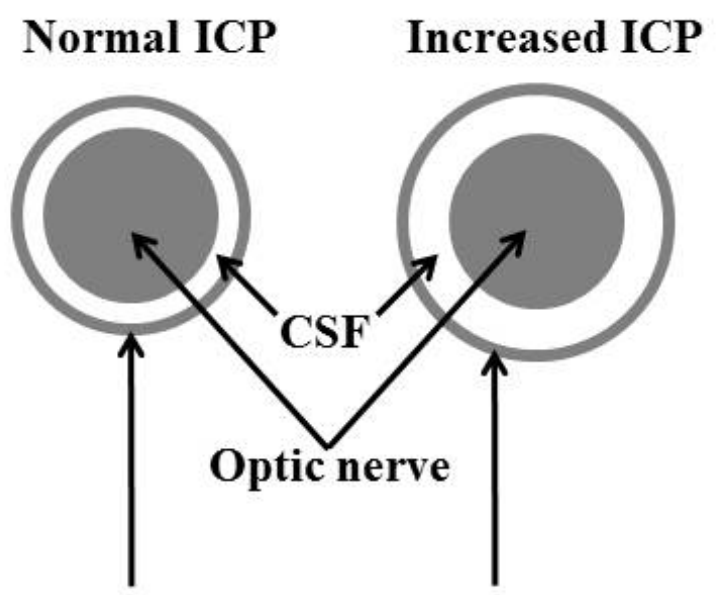

Optic nerve sheath

Fig. 1. The subarachnoid space surrounds the optic nerve and is bounded by the optic nerve sheath that is an anatomical extension of the dura mater around the nerve. In case of increased intracranial pressure (ICP), the optic nerve sheath is dilated due to the elevated cerebrospinal fluid (CSF) pressure.

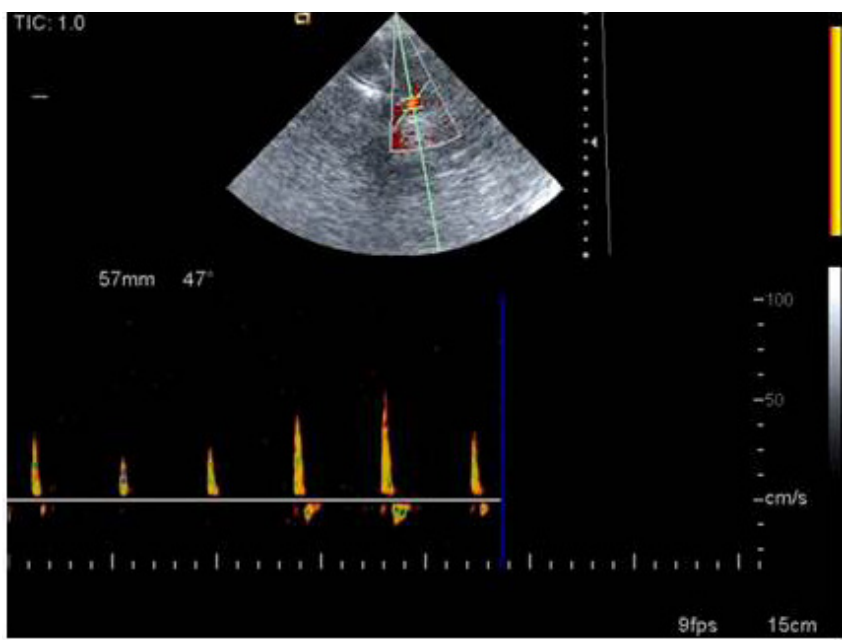

Fig. 2. Systolic spikes detected in the right MCA in brain death.
PSV with no diastolic flow, as well as lack of flow, proves lack of cerebral circulation.

Once oscillating flow is identified, it should be present in both MCAs and the basilar artery and should be registered at two different time points, with a time interval of 30 minutes, to exclude effects of a transient increase in intracranial pressure. TCD alone is not suitable for diagnosing brain death but may shorten the duration of the observation period.

\section{TCD DETECTION OF VASOSPASM CAUSED}

\section{BY SUBARACHNOID HAEMORRHAGE (SAH)}

In non-traumatic SAH due to a ruptured intracranial aneurysm, the primary causes of morbidity are rebleeding and cerebral vasospasm [21-23]. Vasospasm is caused by the release of haemoglobin and its breakdown products into the CSF $[24,25]$. Vasoconstriction of the main intracranial arteries, leading to delayed ischemic damage, was shown to have a significant effect on mortality and morbidity [26]. Vasospasm following SAH most commonly develops after the second day and reaches a maximum at the end of the second week [27-29]. Daily TCD is recommended in all cases of SAH, 3-10 days after the onset of the disease. Serial TCD measurements can be stopped two weeks after the beginning of $\mathrm{SAH}$, if vasospasm does not develop in this period. Otherwise, daily TCD measurements should be performed until the vasospasm resolves. The aim of TCD is to identify early development of a significant vasospasm and to start appropriate treatment to avoid delayed ischemic deficits.

Vasospasm results in increased flow velocity in the affected artery. However, increase in MFV might also be caused by stenosis or hyperaemia. Increased flow velocity due to stenosis usually affects smaller segments of the artery, while vasospasm results in flow velocity increase in longer arterial segments. The Lindegaard ratio, defined as MFV in MCA / MFV in extracranial ICA, differentiates between hyperaemic flow and vasospasm [30]. While hyperaemic flow is associated with higher ICA and MCA flow velocities, vasospasm due to SAH results in flow velocity increase only in intracranial, but not in extracranial arteries, meaning that hyperaemic flow does not influence the Lindegaard ratio significantly. However, in vasospasm, an increase in the Lindegaard ratio is expected. MFV and the Lindegaard ratio are suitable to grade the severity of vasospasm. Criteria for vasospasm in SAH were established for 
MCA and BA (Table 1), but are less reliable for ACA and PCA.

\section{THROMBOLYSIS AND TCD}

TCD and TCCD are useful tools for diagnosing the occlusion of main intracranial arteries. Moreover, TCD with monitoring probes fixed by a headband is suitable for monitor spontaneous or treatment-induced recanalization $[31,32]$. Ultrasound was shown to loosen fibrin bridges resulting in thrombi being dissolved [33]. Although smaller studies suggested that insonation with TCD may augment the lytic effect of the rt-PA [32,34], the CLOTBUST trial failed to confirm a significant clinical benefit, measured at 90 days, of rt-PA treatment and the additional use of low power ultrasound compared to the rt-PA treatment alone [35].

\section{STENOSIS OF THE MAIN INTRACRANIAL}

\section{ARTERIES CAUSED BY SICKLE CELL DISEASE}

Circulating sickled cells and their adherence to the endothelial cells increase the risk of stenosis and occlusion of the main intracranial arteries, including ICA, MCA and ACA [36]. Because the time-averaged mean of the maximum velocity above $170-200 \mathrm{~cm} / \mathrm{s}$ in the middle cerebral artery was associated with an increased risk of stroke [37], and beneficial effect of blood transfusion could reduce the risk of stroke significantly [38], TCD screening is extremely useful in children with sickle cell disease.

\section{MONITORING OF MCA FLOW DURING CAROTID ENDARTERECTOMY}

During carotid endarterectomy, the CCA on the side of the surgery is clamped for the period of disoblitera- tion. However, in case of poor collateral circulation, this type of artificial occlusion of the CCA may result in significant hypoperfusion and stroke. There are several methods to monitor the safety of CCA clamping, including local anaesthesia, somatosensory evoked potential and TCD monitoring. At least 30\% decrease of MCA MFV after clamping of CCA indicates a significant reduction in cerebral flow. Lack of normalisation of the MCA MFV within 1-2 minutes suggests reduced collateral cerebral circulation and the need for shunting during carotid endarterectomy $[39,32]$.

\section{ACKNOWLEDGMENT}

This work was supported by the Hungarian National Brain Research Program, NAP_13-1-2013-0001.

\section{CONFLICT OF INTEREST}

None to declare.

\section{REFERENCES}

1. Aaslid R, Markwalder TM, Nornes H. Noninvasive transcranial Doppler ultrasound recording of flow velocity in basal cerebral arteries. J Neurosurg. 1982;57:769-74.

2. Lindegaard KF, Bakke SJ, Sorteberg W, Nakstad P, Nornes H. A non-invasive Doppler ultrasound method for the evaluation of patients with subarachnoid hemorrhage. Acta Radiol Suppl. 1986;369:96-8.

3. George MS. Neuroactivation and Neuroimaging with SPECT. Springer-Verlag, New York, 1991.

4. Holman BL, Devous MD. Functional brain SPECT: the emergence of a powerful clinical method. J Nucl Med. 1992;33:1888-904.

5. Lindegaard KF, Bakke SJ, Grolimund P, Aaslid R, Huber P, Nornes $H$. Assessment of intracranial hemodynamics in carotid artery disease by transcranial Doppler ultrasound. J Neurosurg. 1985;63:890-8.

6. Kingelhofer J, Conrad B, Benecke R, Sander D, Markakis E.

Table 1. Grading of severity of the vasospasm in the MCA and BA (Aaslid et al., 1984; Lindegaard et al., 1986; Lindegaard et al., 1988; Sviri et al., 2006)

\begin{tabular}{|ccc}
\hline Degree of vasospasm in the MCA & MFV & and \\
Mild (<25\%) & $120-149 \mathrm{~cm} / \mathrm{s}$ & $3-6$ \\
Moderate (25-50\%) & $150-199 \mathrm{~cm} / \mathrm{s}$ & $3-6$ \\
Severe (>50\%) & $>200 \mathrm{~cm} / \mathrm{s}$ & $>6$ \\
Degree of vasospasm in the BA & $\mathbf{M F V}$ & and \\
Mild (may represent vasospasm) & $70-85 \mathrm{~cm} / \mathrm{s}$ & $2.00-2.49$ \\
Moderate (25-50\%) & $>85 \mathrm{~cm} / \mathrm{s}$ & $2.50-2.99$ \\
Severe (>50\%) & $>85 \mathrm{~cm} / \mathrm{s}$ & $\geq 3$ \\
\hline MCA: middle cerebral artery, BA: basilar artery, MFV: mean flow velocity; LR: Lindegard ratio &
\end{tabular}


Available online at: www.jccm.ro

Evaluation of intracranial pressure from transcranial Doppler studies in cerebral disease. J Neurol. 1988;235:159-62.

7. Wakerley BR, Kusuma Y, Yeo LL, Liang S, Kumar K, Sharma AK, Sharma VK. Usefulness of transcranial Doppler-derived cerebral hemodynamic parameters in the noninvasive assessment of intracranial pressure. J Neuroimaging. 2015;25:111-6.

8. Bouzat P, Francony G, Declety P, Genty C, Kaddour A, Bessou P, Brun J, Jacquot C, Chabardes S, Bosson JL, Payen JF. Transcranial Doppler to screen on admission patients with mild to moderate traumatic brain injury. Neurosurgery. 2011;68:1603-10.

9. Sorrentino E, Budohoski KP, Kasprowicz M, Smielewski P, Matta B, Pickard JD, Czosnyka M. Critical thresholds for transcranial Doppler indices of cerebral autoregulation in traumatic brain injury. Neurocrit Care. 2011;14:188-93.

10. Bellner J, Romner B, Reinstrup P, Kristiansson K-A, Ryding E, Brandt L. Transcranial Doppler sonography pulsatility index (PI) reflects intracranial pressure (ICP). Surg Neurol. 2004;62:4551.

11. Moreno JA, E. Mesalles E, Gener J, Tomasa A, Ley A, Roca J, Fernández-Llamazares J. Evaluating the outcome of severe head injury with transcranial Doppler ultrasonography. Neurosurg Focus. 2000;8:1-7.

12. Homburg A-M, Jakobsen M, Enevoldsen E. Transcranial Doppler recordings in raised intracranial pressure. Acta Neurologica Scandinavica. 1993;87:488-493.

13. Hansen HC, Helme K. Validation of the optic nerve sheath response to changing cerebrospinal fluid pressure: Ultrasound findings during intrathecal infusion tests. J Neurosurg. 1997;87;34-40.

14. Helme K, Hansen HC. Fundamentals of transorbital sonographic evaluation of optic nerve sheath expansion under intracranial hypertension. I. Experimental study. Pediatr Radiol. $1966 ; 26 ; 701-5$.

15. Sahu S, Swain A. Optic nerve sheath diameter. A novel way to monitor the brain. J Neuroanaesthesiol Crit Care. 2017; 4, Suppl S1:13-8.

16. Rajajee V, Vanaman M, Fletcher JJ, Jacobs TL. Optic nerve ultrasound for the detection of raised intracranial pressure. Neurocrit Care. 2011;15:506-15.

17. Geeraerts T, Launey Y, Martin L, Pottecher J, Vigué B, Duranteau $J$, et al. Ultrasonography of the optic nerve sheath may be useful for detecting raised intracranial pressure after severe brain injury. Intensive Care Med. 2007;33:1704-11.

18. Barnett SB, Ter Haar GR, Ziskin MC, Rott HD, Duck FA, Maeda K. International recommendations and guidelines for the safe use of diagnostic ultrasound in medicine. Ultrasound Med Biol. 2000;26:355-66.

19. Azevedo E, Teixeira J, Neves JC, Vaz R. Transcranial Doppler and brain death. Transplant Proc. 2000;32:2579-81.

20. Hassler W, Steinmetz H, Gawlowski J. Transcranial Doppler ultrasonography in raised intracaranial pressure and in intracranial circulatory arrest. J Neurosurg. 1988;68:745-51.
The Journal of Critical Care Medicine 2017;3(3) • 103

21. Kassell NF, Boarini DJ. Patients with ruptured aneurysm: Preand postoperative manegement. In: Wilkins RA (ed) Cerebral arterial spasm. Williams and Wilkins, Baltimore London. 1980.

22. Ljunggren $B, B r a n d t ~ L$. The outcome in 100 consecutive cases of early aneurysm surgery. Acta Neurochir. 1982;63:215-9.

23. Ljunggren B, Säveland H, Brandt L. Aneurysmal subarachnoid hemorrhage-historical background from a Scandinavian horizon. Surg Neurol. 1984;22:605-16.

24. Yamamoto Y, Smith RR, Bernanke DH. Accelerated nonmuscle contraction after subarachnoid hemorrhage: Culture and characterization of myofibroblasts from human cerebral arteries in vasospasm. Neurosurgery. 1992;30:337-45.

25. Macdonald RL, Weir BKA. A review of hemoglobin and the pathogenesis of cerebral vasospasm. Stroke. 1991;22:971-82.

26. White $H$, Venkatesh B. Applications of transcranial Doppler in the ICU: a review. Intensive Care Medicine, 2006;32:981-94.

27. Kodama N, Mizoi K, Sakurai Y, Suzuki J. Incidence and onset of vasospasm. In: Wilkins RH (ed) Cerebral arterial spasm. Williams and Wilkins, Baltimore London. 1980.

28. Saito J, Sano K. Vasospasm after aneurysm rupture: Incidence, onset and course. In: Wilkins RH (ed) Cerebral arterial spasm. Williams and Wilkins, Baltimore London. 1980. pp 294-301.

29. Weir B. The incidence and onset of vasospasm after subarachnoid hemorrhage from ruptured aneurysm. In: Wilkins RH (ed) Cerebral arterial spasm. Williams and Wilkins, Baltimore London. 1980. pp 302-5.

30. Lindegaard KF, Nornes H, Bakke SJ, Sorteberg W, NakstadP. Cerebral vasospasm after subarachnoid haemorrhage investigated by means of transcranial Doppler ultrasound. Acta Neurochir. 1988;42:81-4.

31. Alexandrov AV, Grotta JC. Arterial reocclusion in stroke patients treated with intravenous tissue plasminogen activator. Neurology. 2002;59:862-7.

32. Alexandrov AV, Demchuk AM, Felberg RA, Christou I, Barber PA, Burgin WS, Malkoff M, Wojner AW, Grotta JC. High rate of complete recanalization and dramatic clinical recovery during tPA infusion when continuously monitored with 2-Mhz transcranial Doppler monitoring. Stroke. 2000;31:610-4.

33. Polak JF. Ultrasound energy and the dissolution of thrombus. $N$ Engl J Med. 2004;351:2154-5.

34. Eggers J, Koch B, Meyer K, König I, Seidel G. Effect of ultrasound on thrombosis of middle cerebral artery occlusion. Ann Neurol. 2003;53:797-800.

35. Alexandrov AV, Köhrmann $M$, Sinne L, Mandava $P$, Barreto AD, Demchuk AM, Tsivgoulis G, Mikulik R, Brandt G, Alleman J, Grotta JC, Molina CA, Kent TA, Alexandrow WA, Schellinger PD. Ultrasound enhanced thrombolysis for ischemic stroke: results of a multi-national phase III trial (CLOTBUSTER). http:// esoc2016.com/scientific-information-abstracts/webcast\#. WTT1qevyjlU)

36. Platt OS. Prevention and management of stroke in sickle cell anemia. Hematology. 2006:54-7. 
104 The Journal of Critical Care Medicine 2017;3(3)

37. Adams RJ, McKie VC, Carl EM, Nichols FT, Perry R, Brock K, McKie K, Figueroa R, Litaker M, Weiner S, Brambilla D. Longterm stroke risk in children with sickle cell disease screened with transcranial Doppler. Ann Neurol. 1997;42:699-704.

38. Adams RJ, McKie VC, Hsu L, Files B, Vichinsky E, Pegelow C, Abboud M, Gallagher D, Kutlar A, Nichols FT, Bonds DR, Brambilla
Available online at: www.jccm.ro

D. Prevention of a first stroke by transfusions in children with sickle cell anemia and abnormal results on transcranial Doppler ultrasonography. N Engl J Med. 1998;339:5-11.

39. Naqvi J, Yap KH, Ahmad G, Ghosh J. Transcranial Doppler ultrasound: a review of the physical principles and major applications in critical care. Int J Vasc Med. 2013;2013:629378. 